\title{
Fracture Assessment of the Weld-Base Metal Interface of High-Strength Steel Weld Joint
}

\author{
Z. P. Zhong, ${ }^{\text {a,b,1 }}$ H. Liu, ${ }^{\text {a }}$ and J. J. Ma ${ }^{\text {a }}$ \\ ${ }^{a}$ Key Laboratory of C\&PC Structures of the Ministry of Education, Southeast University, Nanjing, \\ China \\ b Department of Civil Engineering, Shanxi University, Taiyuan, China \\ 1zpz_2006@163.com
}

The brittle fracture of the weld joint at low stresses is controlled by high-strength steel characteristics and welding defects. Based on fracture mechanics, the fracture behavior of the weldbase metal interface of a high-strength steel weld joint was studied to reveal the critical locations of the latter. From tensile fracture experiments of 45 steel welded specimens, the load-displacement curve and the fracture modes of weld joints were obtained. The results indicate that the critical loads and fracture modes are influenced by the crack slope angle. The maximum load of interface fracture in weld joints is less than that of the failure in the base metal mainly related to the existence of initial defects in the weld joint. The fracture surface morphology was also detected. It is considered that the fracture surface is influenced by different fracture locations and different microstructure of the weld and base metals. In addition, the critical stress intensity factors of a weld interface crack were calculated based on the critical load and the finite element linear extrapolation method. The linear fracture assessment criteria were proposed, which will be applicable to safety evaluation for the weld joints of high-strength steel structures.

Keywords: high-strength steel weld joint, butt weld, structural performance, interfacial fracture.

Introduction. With rapid economic growth, the construction industry has been made considerable progress and entered into the rapid development period, which brings huge consumption of building materials [1]. In order to achieve sustainable development, it is necessary to develop new building materials to save resources and energy direction, and vigorously promote the use of high-strength steel $[2,3]$. There are many advantages of high-strength steel, such as overall stability factor is much higher than ordinary steel under the same axial compression conditions, reducing the size and weight of the structure, decreasing the welding work and welding material consumption. High-strength steel structure is composed of the components by welding to connect, which plays a structural function. Nevertheless, for large welded structure, the weld joint is found to be weak location from the previous studies owing to the highly heterogeneous material microstructure nature and physical properties (e.g., mechanical, thermal and fracture properties) across the weld joint $[4,5]$. Moreover, defects like welding gas pores, impurities and residual stresses will be brought into inevitably during the welding process, which significantly cause the stress concentration in the weld joints $[6,7]$. The crack continuous propagation leads to the failure of welded structure and may cause accidents $[8,9]$. In order to achieve an accurate integrity assessment for the welded structure, the fracture performance and mechanical properties in weld joint locations should be studied and properly estimated, and the reasonable failure assessment criterion should be set up.

As the strength of steel increases, the plasticity and toughness of the steel is decreased correspondingly. According to the equal strength matching principle, the actual strength of the weld metal should be higher than the actual strength of the base high-strength metal after the welding process [10]. However, in terms of the toughness of the weld joint, the 
toughness of weld joint decreased accordingly [7]. Hence, besides the strength of weld joints is satisfied strength requirement, the fracture toughness of weld joints also should be considered in weld joints [11]. Some studies on the fracture behavior for weld joints have been performed. Jang et al. [12] conducted a research on the fracture resistance, local tensile properties and microstructures of weld joints between the low alloy steel and 316 stainless steel using Alloy82/182. The measurement of strength and fracture toughness along the thickness of the weld as well as across the weld was conducted. The result indicates that the fracture toughness decreases with the increase of yield strength. Laukkanen et al. [13] performed a research on the fracture behavior for various regions of SA508 and AISI304 DMWJ. Two major failure types are found, rapid crack propagation towards the fusion line and another fracture form situated near the fusion line. Wang et al. [14] carried out an experimental investigation of local fracture resistance and crack growth behavior in Alloy52M dissimilar metal weld joint by using the single-edge notched bend (SENB) specimens. Their results showed that the fracture assessment of base metals or weld metals is unsafe without considering the influence of material properties such as interface zone and heat affected zone (HAZ). Kirk et al. [15] examined the validity of failure behavior for structurally relevant situations and the result measured by experiment. Krasovskii et al. [8] studied the evaluation of cracking in dissimilar metal welds. Samal et al. [4] discussed the fracture behavior of a dissimilar metal weld joint crack growth paths by using single-edged notched bend type of specimens with initial cracks located at different positions of the weld joints.

From the studies above, we found that the weld joint is critical position and the complete assessment of weld joint should include fracture evaluation over interface zone, near interface zone and heat affected zone. However, the previous cracks were mainly limited in weld metal or base metal, which may not reflect fracture resistance behaviors when the initial cracks are located at another location (e.g., fusion-line interfaces between different materials or near interfaces, etc.). In this study, the local fracture resistance behaviors of initial crack on fusion-line interface of the single edge-notched weld specimens are studied. By tensile fracture experiment of 45\# low alloy high-strength steel weld joint specimens, the critical force and the failure modes of instable cracking is obtained. The effects of the various angle of inclination on local fracture resistance properties, crack propagation path and security assessment are discussed. What's more, a comparison of fracture behaviors of welded specimen and base metal is provided.

1. Experimental Program of Butt weld joint. Welding is an effective and reliable connection method, which makes the component of steel connect to another. Due to the particularity of the welding process, the welding defect is inevitable, which leads weld joint to produce brittle fracture at low stress, and significantly reduces the carrying capacity of welding structure. Besides the material itself, the manufacturing process and the circumstance of service whose defects are also include in engineering structures. The existence of defects increases the likelihood of structure failure, and reduces the carrying capacity of the structure. In this experiment, seven groups of $45 \#$ steel butt weld specimen were designed by the requirement of the Chinese national standard "structural welding code-steel" GB 50661-2011 [16]. The tensile mechanical properties of the welding specimen, such as axial tensile load and deformation data automatic acquisition by the IMP data acquisition system by tensile fracture experiment of $45 \#$ steel.

2. Specimen Design. The geometric dimension of the specimens is shown in Fig. 1. The specimen length $L$ is $380 \mathrm{~mm}$, the gauge length $L_{g}$ is $230 \mathrm{~mm}$, the chamfer radius $R$ is $25 \mathrm{~mm}$, the width $W$ is $10 \mathrm{~mm}$ and crack depth $a / W$ is set to be 0.5 . The weld joints for experiment were taken from 45\# low alloy high-strength steel and ER316 welding metal, whose chemical composition and mechanical properties as shown in Table 1. The welding process was conducted with $10 \mathrm{~mm}$ thick low-alloy rolling steel, double- $\mathrm{V}$ groove, $\mathrm{CO}_{2}$ gas shielded welding, in accordance with GB 50661-2011 [16]. The welding current, voltage, 
$\mathrm{T}$ a b 1 e 1

Chemical Compositions and Mechanical Properties of Joint Metal

\begin{tabular}{|c|c|c|c|c|c|c|c|c|c|c||}
\hline \hline \multirow{2}{*}{ Material } & \multicolumn{6}{|c|}{ Chemical components (mass percentage \%) } & \multicolumn{3}{c|}{$\begin{array}{c}\text { Physical and mechanical } \\
\text { properties }\end{array}$} \\
\cline { 2 - 10 } & $\mathrm{C}$ & $\mathrm{Si}$ & $\mathrm{Mn}$ & $\mathrm{Cr}$ & $\mathrm{Ni}$ & $\mathrm{Cu}$ & $\mathrm{Fe}$ & $\begin{array}{c}\text { Yield } \\
\text { strength } \\
\sigma_{s}, \mathrm{MPa}\end{array}$ & $\begin{array}{c}\text { Tensile } \\
\text { strength } \\
\sigma_{m}, \mathrm{MPa}\end{array}$ & $\begin{array}{c}\text { Elongation, } \\
\%\end{array}$ \\
\hline 45\# steel & $\begin{array}{c}0.42 \sim \\
0.50\end{array}$ & $\begin{array}{c}0.17 \sim \\
0.37\end{array}$ & $\begin{array}{c}0.50 \sim \\
0.80\end{array}$ & $\leq 0.25$ & $\leq 0.30$ & $\leq 0.25$ & Bal. & 355 & 600 & 16 \\
\hline ER316 & 0.08 & $\begin{array}{c}0.30 \sim \\
0.65\end{array}$ & $\begin{array}{c}0.10 \sim \\
2.5\end{array}$ & $\begin{array}{c}1.8 \sim \\
2.0\end{array}$ & $11 \sim 14$ & - & Bal. & 310 & 520 & 30 \\
\hline \hline
\end{tabular}
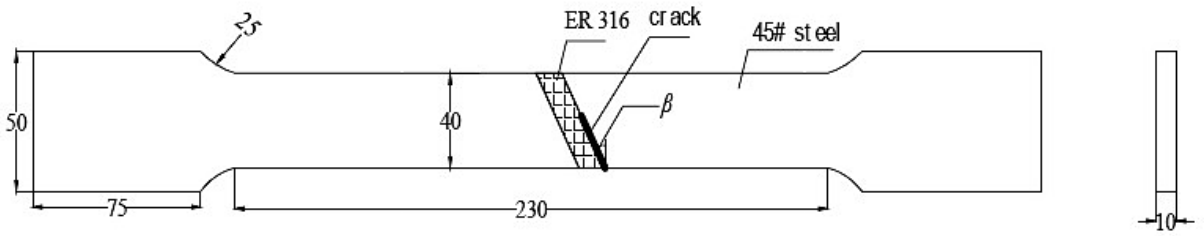

$\mathrm{a}$
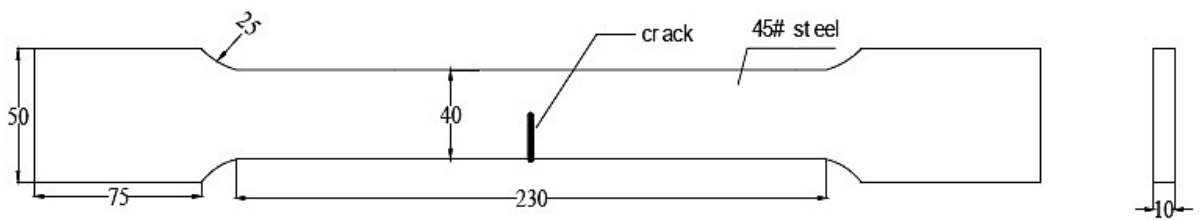

b

Fig. 1. Specimens for the 45\# steel: (a) weldment; (b) with notch (unit: $\mathrm{mm}$ ).

and welding speed are $300 \mathrm{~A}, 30 \mathrm{~V}$, and $1.75 \mathrm{~mm} / \mathrm{s}$, respectively. Before welding, the samples were derusted, cleaned, polished, and slaged. To reduce martensite and improve fracture toughness of the weld joints, a preheat treatment (keep $250^{\circ} \mathrm{C}$ for $15 \mathrm{~h}$ ) was carried out before welding. To eliminate the residual stress and prevent cracking, the weldment is put into incubator under postheat treatment temperature of $600^{\circ} \mathrm{C}$ for $2 \mathrm{~h}$, then furnace cooling. The weld joint inclination angle is $0,15,30,45$, and $60^{\circ}$. The weld tumor is removed after welding finally. In order to investigate fracture resistance and understand the crack growth behavior of the interfaces at fusion lines, an initial crack has been machined on interface between welding material and base metal shown in Fig. 1a. The products of weld joints are seen in Fig. 2a. In addition, the specimens performed with a set of $0^{\circ}$ crack specimens without welding are compared with the fracture toughness value of weld joint shown in Fig. $2 b$.

3. Tensile Fracture Experiment of 45\# Steel. The uniaxial tensile fracture tests of $45 \#$ steel were performed on the sandwiched plate specimens using a hydraulic universal testing machine (Fig. 3a) with a $300 \mathrm{kN}$ load cell to measure critical the load. All tests were conducted by displacement control at a cross-head speed of $1.0 \mathrm{~mm} / \mathrm{min}$. During the tests, the load and load point displacement were both automatically recorded by a computer aided control system of the testing machine. When the load increases to critical value, the welding specimens fracture occurs and the test is completed. The typical failure modes or the interface crack growth path is seen in Fig. $3 b$. 

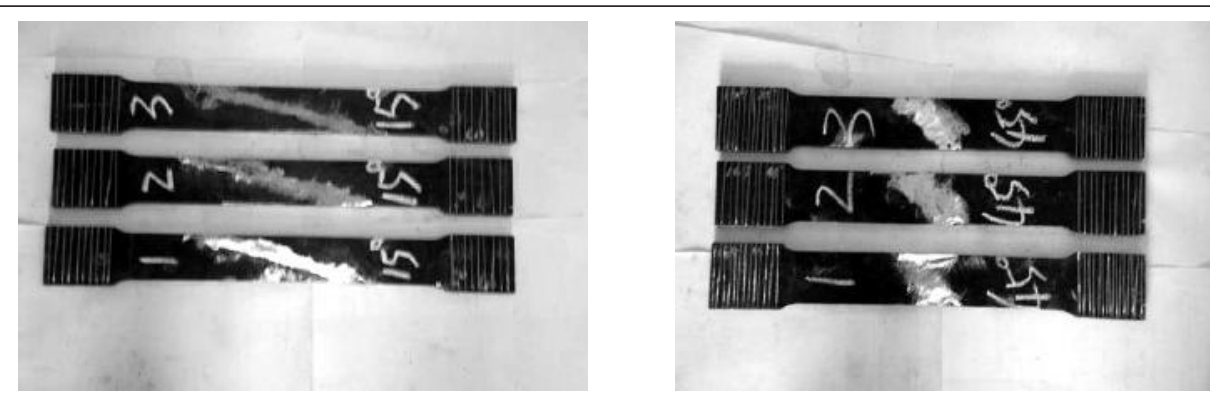

a

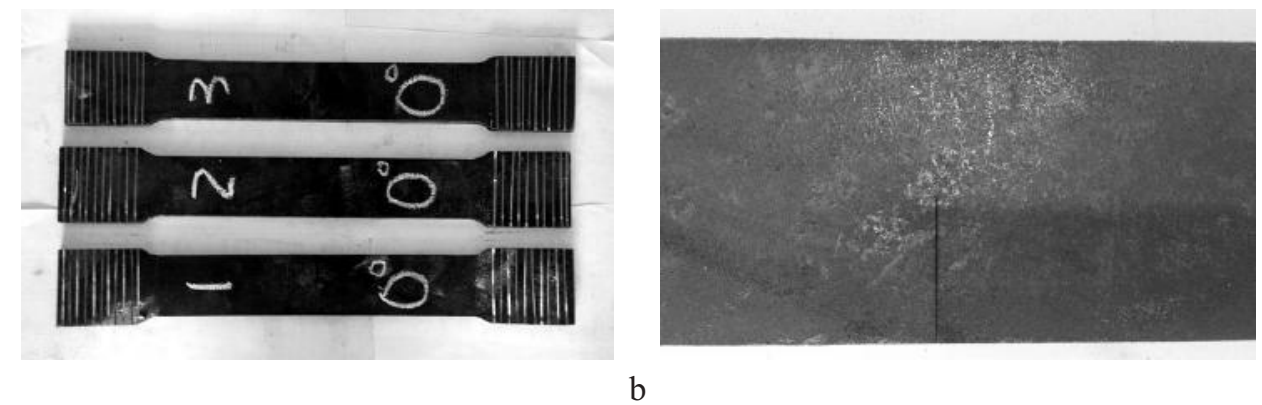

Fig. 2. Some products of weld joint configurations (a) and illustration of $45 \#$ steel without welding (b).

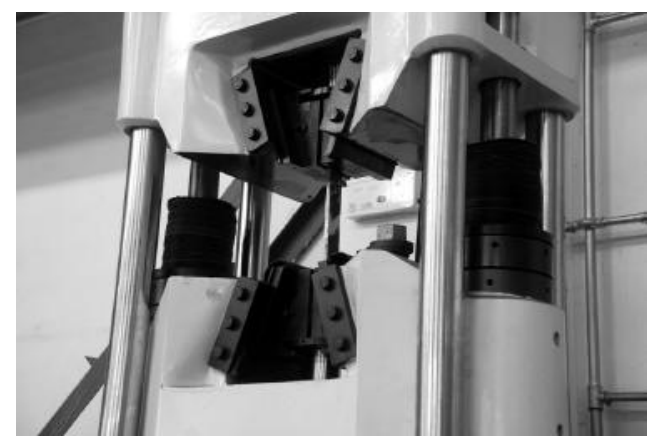

a

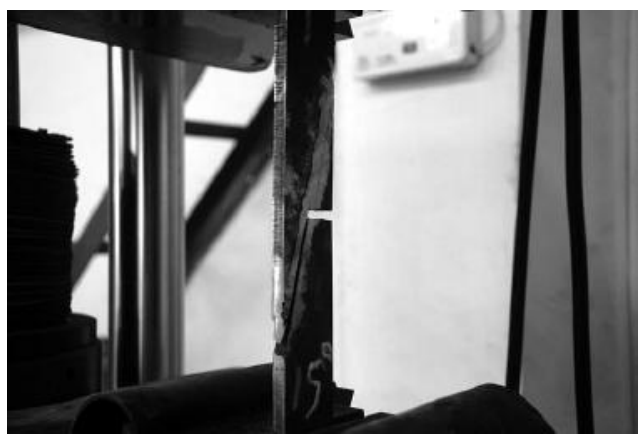

b

Fig. 3. Set-up for the uniaxial tensile tests (a) and failure pattern of welded specimen (b).

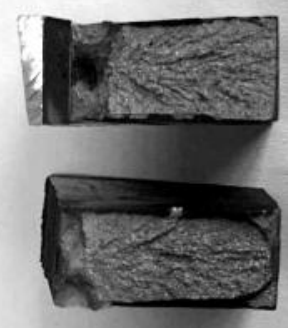

a

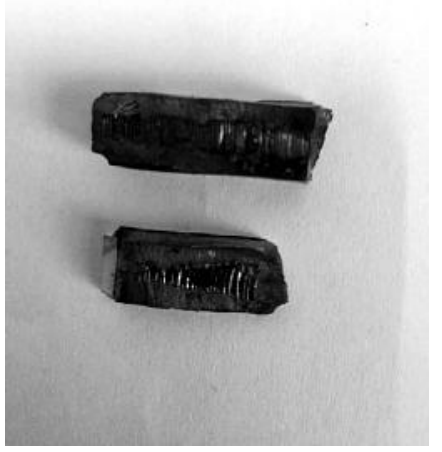

b

Fig. 4. Macroscopic observations for fracture surfaces: (a) base metal fracture; (b) interface fracture. 
4. Results and Discussion. The statistics of specimen failure load and failure mode are shown in Table 2. It can be seen from the results that without the welding crack, the failure does not occur on the joint weld position, but happens on weak part of base metal. Due to the base metal failure of weld joint, the tensile strength is a reflection of the performance characteristics of the parent material. When the initial notch was on the interface of welding metal and base metal, the tested specimens was failed by a welding metal and base metal interface separation for the crack inclination angle $\beta$ between the load and the crack surface is $0^{\circ}$. As the inclination angle increase, and the angle is within $0<\beta \leq 30^{\circ}$, the precrack, which was located on the welding metal and base metal interface, kinked into the base metal once reaching the peak load. It is important to note that the flat fracture surface without macroscopic plastic deformation and small white crystal can be seen clearly in Fig. 4a, indicating that brittle crack growth in the base metal. When inclination angle $30<\beta \leq 60^{\circ}$, besides fracture in base metal, a brittle fracture process took place along the interface between the welding metal and base metal, which the fracture surface is observed in Fig. 4b. It can be obtained from Table 2, when $\beta>30^{\circ}$, the possibility of weld location failure is increased and weld joint becomes the weak position of the welding structure for interface crack tip under the condition of tensile and shear stress.

$\mathrm{T}$ a b 1 e 2

Experimental Result of the weld joint Specimens

\begin{tabular}{|c|c|c|c|c|}
\hline \multicolumn{2}{|c|}{ Specimen type } & \multirow{2}{*}{$\begin{array}{c}\text { Section area } \\
\qquad A, \mathrm{~mm}^{2} \\
400\end{array}$} & \multirow{2}{*}{$\begin{array}{c}\text { Ultimate load } \\
\qquad P_{u}, \mathrm{kN} \\
94.49\end{array}$} & \multirow{2}{*}{$\begin{array}{c}\text { Failure mode } \\
\text { Base metal fracture }\end{array}$} \\
\hline Initial crack & 1 & & & \\
\hline in $45 \#$ steel & 2 & 400 & 92.93 & Base metal fracture \\
\hline & 3 & 400 & 90.75 & Base metal fracture \\
\hline \multirow{3}{*}{$\begin{array}{c}\text { No crack } \\
\text { in weld joint }\end{array}$} & 1 & 400 & 256.28 & Base metal fracture \\
\hline & 2 & 400 & 256.03 & Base metal fracture \\
\hline & 3 & 400 & 255.92 & Base metal fracture \\
\hline \multirow[t]{3}{*}{$0^{\circ}$} & 1 & 400 & 99.23 & Interface fracture \\
\hline & 2 & 400 & 102.26 & Interface fracture \\
\hline & 3 & 400 & 100.93 & Interface fracture \\
\hline \multirow[t]{3}{*}{$15^{\circ}$} & 1 & 400 & 104.95 & Base metal fracture \\
\hline & 2 & 400 & 117.73 & Base metal fracture \\
\hline & 3 & 400 & 98.21 & Base metal fracture \\
\hline \multirow[t]{3}{*}{$30^{\circ}$} & 1 & 400 & 83.28 & Interface fracture \\
\hline & 2 & 400 & 98.52 & Base metal fracture \\
\hline & 3 & 400 & 100.16 & Base metal fracture \\
\hline \multirow[t]{3}{*}{$45^{\circ}$} & 1 & 400 & 91.10 & Base metal fracture \\
\hline & 2 & 400 & 75.27 & Interface fracture \\
\hline & 3 & 400 & 84.66 & Interface fracture \\
\hline \multirow[t]{3}{*}{$60^{\circ}$} & 1 & 400 & 72.42 & Interface fracture \\
\hline & 2 & 400 & 91.48 & Interface fracture \\
\hline & 3 & 400 & 93.71 & Base metal fracture \\
\hline
\end{tabular}



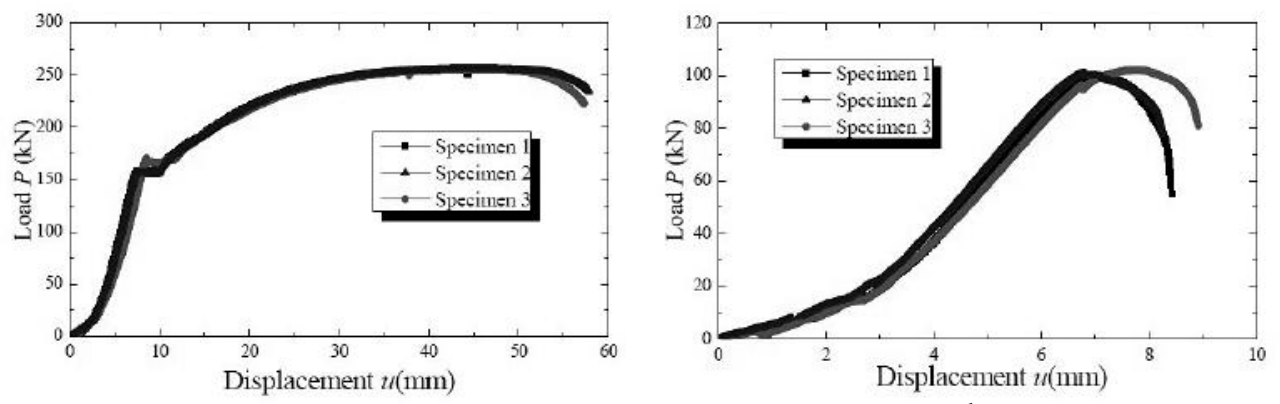

a

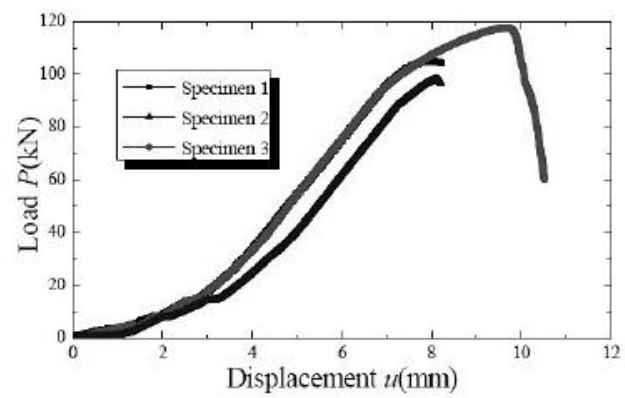

c

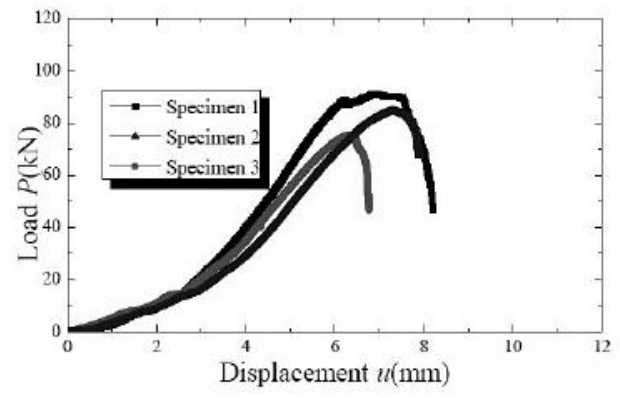

e

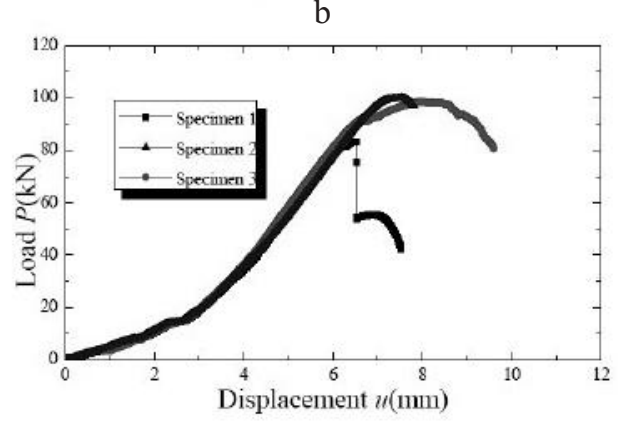

d
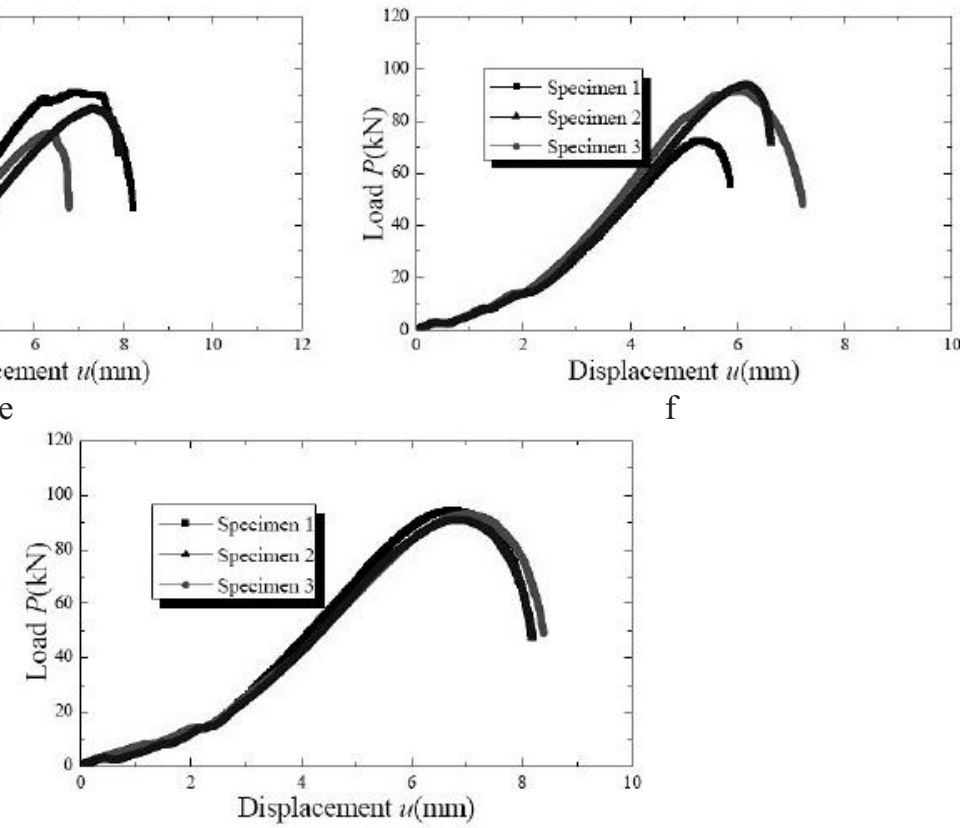

$\mathrm{g}$

Fig. 5. Load-displacement curve of (a) $0^{\circ}$ crack-free, (b, c, d, e, f) 0, 15, 30, 45, and $60^{\circ}$, respectively, and $(\mathrm{g}) 0^{\circ}$ crack without welding.

Figure 5 give load-displacement curves of crack-free welded steel plate, weld-free crack plate and weld crack at different slanting angle $\beta$. According to the figures, it is shown that the specimen exhibits good plasticity for no cracked specimen and the limit displacement ratio is 7 times compare to the initial crack specimen, which is more reflection of the mechanical properties of the base metal. However, the ductility is poor for 
initial crack steel shown in Fig. $5 \mathrm{~b}-5 \mathrm{~g}$. When specimens increase to the maximum load $\left(P_{\max }\right)$, the crack extension occurs and then load has decreased with increasing of displacement. Another interesting finding is that the maximum load of interface failure of weld joints is smaller than the critical load on failure in base metal, which also indicates weld joint is a weak position for welded structure. This exhibits that the welding quality is very important as it had an effect on the ultimate bearing capacity of welded specimens.

5. Determination of Stress Intensity Factors. As shown in the Fig. 6, the stress field and displacement field at the crack tip region can be written [17]:

$$
\sigma_{i j}=\frac{K_{m}}{\sqrt{2 \pi r}} f_{i j}(\theta), \quad u_{i}=\frac{K_{m}}{\mu} \sqrt{\frac{r}{2 \pi}} g_{i}(\theta) .
$$

It can be seen from the Eq. (1) that stress at crack tip is singularity of $r^{-1 / 2}$, when $r \rightarrow 0$, the stress component. Thus, it is difficult to evaluate the condition of crack propagation by strength theory established by the traditional materials mechanics method. In order to avoid the singularity, the concept of stress intensity factors ( $m=$ I, II) are introduced. From the displacement component on the crack surface, the stress intensity factors are expressed as follows:

$$
K_{\mathrm{I}}=\frac{2 \mu}{\kappa+1} \lim _{r \rightarrow 0}\left[\Delta v \sqrt{\frac{2 \pi}{r}}\right], \quad K_{\mathrm{II}}=\frac{2 \mu}{\kappa+1} \lim _{r \rightarrow 0}\left[\Delta u \sqrt{\frac{2 \pi}{r}}\right],
$$

where $\Delta v=v_{A}-v_{B}, \Delta u=u_{A}-u_{B}, u_{A}, v_{A}, u_{B}$, and $v_{B}$ are the $x$ and $y$ displacements of $A$ and $B$ points corresponding to the crack surface. Nearby the vicinity of the crack tip, assuming $\Delta u / \sqrt{r}=a r+b$, and the stress intensity factor at the crack tip can be obtained by taking the displacement value of several points on both sides of the crack near the crack tip and by linearly interpolating the Eq. (2).

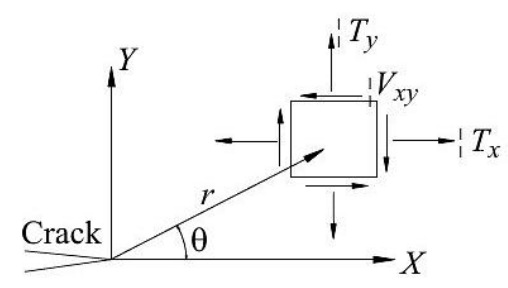

Fig. 6. Relation graph of stress field and displacement field in crack tip region.

6. Numerical Model. The location and loading of the unilateral crack are shown in Fig. 7a. The tensile force at both ends is $P_{0}$, the length of the plate is $230 \mathrm{~mm}$, the width is $40 \mathrm{~mm}$, the length crack is $a$, the angle of the crack is $\beta$, the elastic modulus of the material is $210 \cdot 10^{3} \mathrm{MPa}$, and the Poisson's ratio is 0.3 . Finally, the crack tip is subdivided in order to improve the computational accuracy by FEPG finite element program [18], and the finite element model is shown in Fig. 7b. The stress intensity factor of crack tip $K_{\mathrm{I}}$, $K_{\mathrm{II}}$ is solved by Eq. (2). The variation of the normalized stress intensity factor $\hat{K}_{m}=$ $=K_{m} / P_{0} \sqrt{\pi a}$ with the tip distance $d[d=(a-x) / a]$ is shown in Fig. 8. As can be seen from the figure, when $0.1<d<0.5, \hat{K}_{m}$ with $d$ showed an approximate linear change, so select the curve as a linear extrapolation range. Based on the linear extrapolation method, the critical stress intensity factor of the weld with different inclination angle is shown in Table 3. 
$\mathrm{T}$ a b 1 e 3

The Mean Value of Critical Load Test $P_{c}$ and Fracture Toughness Value $K_{m c}$

\begin{tabular}{|c|c|c|c|}
\hline$\beta, \operatorname{deg}$ & $P_{c}, \mathrm{kN}$ & $K_{\mathrm{Ic}}, \mathrm{MPa} \cdot \mathrm{mm}^{1 / 2}$ & $K_{\mathrm{IIc}}, \mathrm{MPa} \cdot \mathrm{mm}^{1 / 2}$ \\
\hline 0 & 100 & 1250 & 0 \\
\hline 15 & 107 & 1177 & 180 \\
\hline 30 & 94 & 1052 & 325 \\
\hline 45 & 85 & 850 & 420 \\
\hline 60 & 86 & 580 & 450 \\
\hline
\end{tabular}

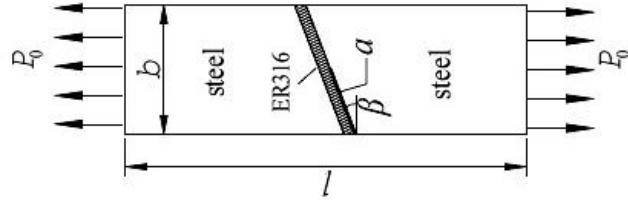

a

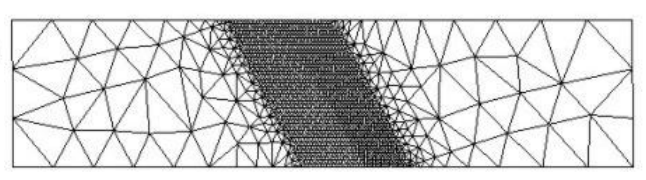

$\mathrm{b}$

Fig. 7. The position and loading condition of specimen (a) and the grid of tensional specimen (b).
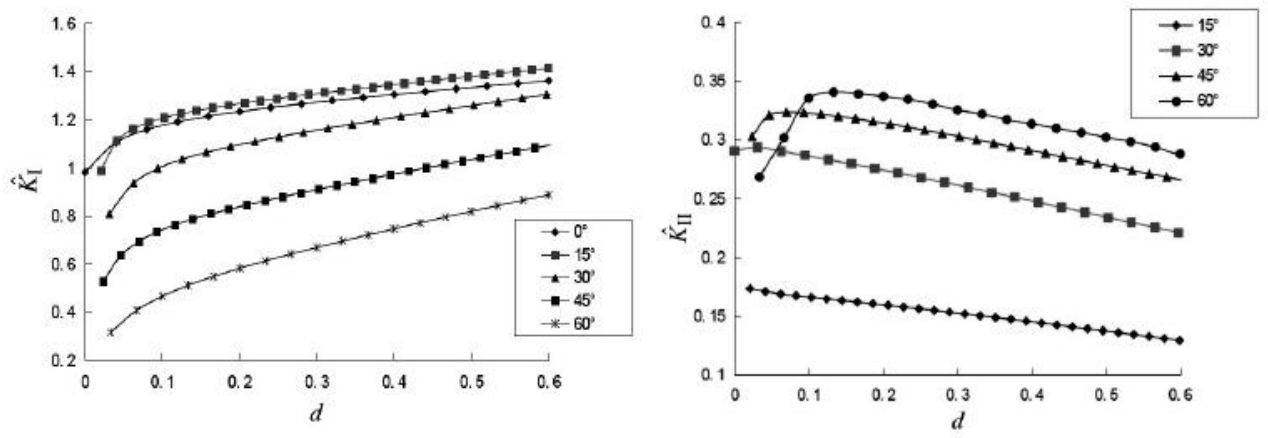

Fig. 8. The curve of normalized stress intensity factor $\hat{K}_{m}(m=\mathrm{I}$, II) with the crack tip distance $d$.

7. Fracture Criterion. Table 3 shows the critical value of the failure load corresponding to the weld crack propagation. The critical stress intensity factor $K_{\mathrm{I} c}, K_{\mathrm{II} c}$ is calculated by linear extrapolation method. As can be seen from Table 3, although the welded inclined angles $\beta$ is changed, but the sum of $K_{\mathrm{I} c}$ and $K_{\mathrm{II} c}$ is a constant, which is equal to $0^{\circ}$ corresponds to $K_{\mathrm{I} c}$. Therefore, we can obtain the fracture criterion of high-strength steel weld: $K_{\mathrm{I}}+K_{\mathrm{II}}=K_{\mathrm{Ic}}$.

Conclusions. By fracture tests of weld joint of high-strength steel with initial crack machined at welding metal/base metal using $45 \#$ steel plate specimen, we got the load-displacement curve of precracked butt weld joint, which indicates that the tensile ductility of $45 \#$ precracked steel butt weld is poor, and the pre-cracked steel specimens unstable fracture occurs after exceeding the critical load. The weld joints did not fracture for crack-free welded steel plate, but was failed on a weak position of the steel. When the prefabricated weld crack is on the interface, for the welded slope angle $\beta<30^{\circ}$, the weld joint was the base metal fracture, and the section perpendicular to the plate axis. And when the angle of weld is $45^{\circ}$, the tensile failure angle is close to $45^{\circ}$, that is to say, the interface failure mode, which belongs to pure shearing stress state and failure morphology. When the slope angle $\beta>45^{\circ}$, the welding interface fracture is typical fracture mode. The phenomenon 
showed that the interface fracture toughness of the joint with the crack situated on interface is the minimum in comparison of base metal and weld metal. Hence, the improvement of the performance resisting to interfacial fracture of welded connections and the established welding interface safety evaluation is important in design and fabrication of welded steel structure. The finite element software was used to simulate the test specimen effectively. The critical stress intensity factor of cracked weld structure was calculated based on the critical load and the linear extrapolation of displacement. A linear fracture assessment criteria was proposed, which can be used as a reference for the determination of interface fracture properties of high-strength steel weld joints.

Acknowledgements. The work is supported by the Fundamental Research Funds for the Central Universities (126545010), the supported by Southeast University, Key laboratory of concrete and pre-stressed concrete structure of Ministry of Education (CPCSME2015-03).

1. J. Wang, J. D. Zhao, and Z. Y. Hu, "Review and thinking on development of building industrialization in China," China Civil Eng. J., 49, No. 5, 1-8 (2016).

2. D. Arsić, M. Djordjević, J. Zivković, et al., "Experimental-numerical study of tensile strength of the high-strength steel S690QL at elevated temperatures," Strength Mater., 48, No. 5, 687-695 (2016).

3. P. Može, D. Beg, and J. Lopatic, "Net cross-section design resistance and local ductility of elements made of high-strength steel," J. Constr. Steel Res., 63, No. 11, 1431-1441 (2007).

4. M. K. Samal, M. Seidenfuss, E. Roos, and K. Balani, "Investigation of failure behavior of ferritic-austenitic type of dissimilar steel weld joints," Eng. Fail. Anal., 18, No. 3, 999-1008 (2011).

5. N. Guo, Z. Yang, M. Wang, et al., "Microstructure and mechanical properties of an underwater wet welded dissimilar ferritic/austenitic steel joint," Strength Mater., 47, No. 1, 12-18 (2015).

6. S. V. Kobel'skyi, S. M. Ban'ko, and V. V. Kharchenko, "Determination of stress intensity factors in the weld joint between the header and shell of PGV-1000M steam generator with a defect in the form of a cavity with a crack," Strength Mater., 47, No. 2, 297-301 (2015).

7. H. W. Lee, W. H. Choe, J. U. Park, et al., "Weld metal hydrogen assisted cracking in $50 \mathrm{~mm}$ TMCP steel plate with SAW process," Sci. Technol. Weld. Joi., 11, No. 3, 243-249 (2013).

8. A. Ya. Krasovskii, I. V. Orynyak, E. E. Gopkalo, "Fractography of in-service fracture of the metal in weld joint No. 111 of the steam generator of a WWER-1000 power unit," Strength Mater., 47, No. 5, 670-678 (2015).

9. P. J. Budden and I. Curbishley, "Assessment of creep crack growth in dissimilar metal welds," Nucl. Eng. Des., 197, Nos. 1-2, 13-23 (2000).

10. R. Kandrotaitè-Janutienè and A. Baltušnikas, "Investigation of plastic behavior of alloyed steel deformed during martensitic transformation," Strength Mater., 48, No. 5, 696-703 (2016).

11. M. K. Samal, K. Balani, M. Seidenfuss, and E. Roos, "An experimental and numerical investigation of fracture resistance behaviour of a dissimilar metal weld joint," $P$. $I$. Mech. Eng. C - J. Mec., 223, No. 7, 1507-1523 (2009).

12. C. Jang, J. Lee, J. S. Kim, et al., "Mechanical property variation within Inconel 82/182 dissimilar metal weld between low alloy steel and 316 stainless steel," Int. J. Pres. Ves. Pip., 85, No. 9, 635-646 (2008). 
13. A. Laukkanen, P. Nevasmaa, U. Ehrnstén, and R. Rintamaa, "Characteristics relevant to ductile failure of bimetallic welds and evaluation of transferability of fracture properties," Nucl. Eng. Des., 237, No. 1, 1-15 (2007).

14. H. T. Wang, G. Z. Wang, F. Z. Xuan, and S. T. Tu, "An experimental investigation of local fracture resistance and crack growth paths in a dissimilar metal weld joint," Mater. Design, 44, 179-189 (2013).

15. M. T. Kirk, K. C. Koppenhoefer, and C. F. Shih, "Effect of constraint on specimen dimensions needed to obtain structurally relevant toughness measures," in: E. M. Hackett, K.-H. Schwalbe, and R. H. Dodds (Eds.), Constraint Effects in Fracture, STP 1171, ASTM International, West Conshohocken, PA (1993).

16. GB 50661-2011. Code for Welding of Steel Structures, Chinese Standard, Implemented on August 1, 2012.

17. S. Maiti, Fracture Mechanics: Fundamentals and Applications, Cambridge University Press (2015).

18. G. P. Liang, Finite Element Language and Its Application [in Chinese], Science Press, Beijing (2013).

Received 15. 09. 2017 